\title{
Semiparametric Base-Independent Equivalence Scales and the Cost of Children in Switzerland
}

\author{
Aline Bütikofer ${ }^{a}$
}

JEL-Classification: D12, C14, J12

Keywords: Semiparametric estimation; Equivalence scales; Engel curves.

\section{Introduction}

Economic data usually report expenditures made by households. However, individual levels of well-being must be known for the evaluation of social policies and the measurement of inequality and poverty. Due to economies of scale in consumption the increase in the needs of a household for an additional household member is not proportional. Shared public goods like living space or household heating expand the production and consumption opportunities of a multi-person household. Therefore, it is important to take the economies of scale into account when making comparisons of economic well-being across households. So-called household equivalence scales are constructed to compare incomes and expenditures of different household types. Formally, equivalence scales are defined as the ratio of the expenditures of two different household types with the same standard of living. For example, a couple household does not need twice the expenditure level of a single person to be equally well-off. This couple household will therefore have an equivalence scale between one and two. The more goods a couple can share, the closer the equivalence scale will be to one. By assigning a value in proportion to its needs to each household type, equivalence scales capture the extent to which household expenditures can be shared and are able to provide a measure of inter-household comparison of welfare.

More precisely, equivalence scales measure the expenditures of a family of a given size and demographic composition, relative to the expenditures of a reference family, when both families attain the same level of utility. If, for example,

a Norwegian School of Economics, Department of Economics, Helleveien 30, 5045 Bergen, Norway, email: aline.buetikofer@nhh.no. The paper was written while the author was at the University of Bern, Switzerland. Without implication, I want to thank Michael Gerfin and two anonymous referees for their valuable comments. All errors are my own. 
a couple has an expenditure level of CHF 30,000 and the scale for comparing couple households to single adult households is 1.5 , the couple household is equivalent, for welfare purposes, to two single adult households who spend CHF 30,000 / 1.5 = CHF 20,000 each.

Equivalence scales are an important tool for applied welfare analysis (see, e.g., Lewbel, 1989; Nelson, 1993). They are used for social evaluation as poverty analysis, to compute social benefit payments, life insurance, or alimony. Equivalence scales are also indispensable for the analysis of income inequality within and between countries (see Jenkins, 1991). Furthermore, the concept of equivalence scale can be used as an indirect measure of the cost of children (see, e.g., Muellbauer, 1974; Browning, 1992; Pashardes, 1991; Lyssiotou, 1997), which serve as the basis for the system of child benefits in many countries. The main goal of this paper is to provide estimates of equivalence scales and child costs for Switzerland.

Three types of equivalence scales are proposed and examined: expert scales, subjective equivalence scales and consumption-based equivalence scales. Expert scales are base on the opinion of social security experts (e.g. Swiss Conference of Social Security or the OECD scales) and are often criticized for their lack of theoretical justification. Subjective equivalence scales are identified based on surveys that ask respondents to either report their happiness (and hence utility) on an ordinal scale, or ask how their utility would change in response to changes in household characteristics. Kapteyn and van PraAg (1978), for example, estimate equivalence scales based on surveys where households are asked how much income they think a family of their type requires to reach a specified level of satisfaction, e.g. 'excellent' or 'sufficient'. The hypothetical nature of the questions has been pointed to as a disadvantage of this approach. Identification requires comparability of these ordinal utility measures and respondents may have little experience of such levels. This paper aims to estimate consumption-based equivalence scales. This concept is based on consumer theory and households' consumption behavior and dates back to ENGEL (1895). Engel observed that richer households tend to spend a smaller share of their total budget on food than poorer households. He therefore proposed to use a household's share of food expenditure as a measure of households' standard of living. The resulting Engel equivalence scale is defined as the ratio of incomes of two different sized households that have the same budget share for food. Similar to Engel scales, Rotнiarth (1943) equivalence scales are defined as the ratio of incomes of two households of different size when each household purchases the same quantity of so-called adult goods (alcohol, tobacco, or adult clothing). BARTEN (1964) constructed a different Engel type scale for every good people purchase. These Barten scales 
correspond to a different measure of economies of scale for each good. Modern consumption-based equivalence scales measure utility using expenditure functions estimated from consumer demand data via revealed preference theory. The revealed preference theory implies that demand data identify the shape and ranking of consumer's indifference curves over bundles of goods. Hence, one set of indifference curves for the reference household and another set for the nonreference household can be identified due to revealed preferences over goods. In conclusion, the estimation of consumption-based equivalence scales is based on consumer theory and the results are obtained from comprehensive datasets. These are the most important advantages of consumption-based equivalence scales compared to the two other approaches of determining equivalence scales.

However, the revealed preferences over goods cannot identify the actual level of well-being for each indifference curve. There is no way of observing which indifference curve of the non-reference household yields the same level of well-being as any given indifference curve of the reference household. Therefore, additional information or not testable restrictions on preferences over the two household types are needed to identify the level of the equivalence scales. To solve this identification problem, LEWBEL (1989) proposes to assume that the equivalence scale function is independent from utility. Under this so-called 'base independence' assumption, preferences obey the property that equivalence scales will not vary across household income levels. ${ }^{1}$ This assumption allows for a meaningful interpretation of equivalence scales for policy purposes. However, base independence is based on the strong assumption that the equivalence scale is the same for all households with equal characteristics across all utility levels. More precisely, the equivalence scale is independent of expenditures or, equivalently, utility. Assume, e.g., we observe two households with equal characteristics. One household's total expenditures are CHF 1000 and the second household's total expenditures are CHF 100,000. Since the base independence assumption implies that the equivalence scale is the same for all households with equal characteristics, both households face the same equivalence scale and therefore also the same relative marginal cost of a further household member. If we assume that this scale is 1.1, the first household will need CHF 100 to be equally well-off with an additional household member and the second household will need CHF 10,000 to maintain the same standard of living.

In empirical applications, consumption-based equivalence scales were mainly estimated using fully parametric linear demand systems (see, e.g., BLUNDELL and Lew bel, 1991; Dickens, Fry and Pashardes, 1993). Empirical evidence,

1 Blackorby and Donaldson (1993) call this condition 'equivalence scale exactness'. 
however, has shown that the demand functions of households are often nonlinear (see, e.g., Blundell, Pashardes and Weber, 1993). Furthermore, the base independence assumption was mostly rejected in parametric models. However, the rejection of base independence from a statistical perspective does not necessarily invalidate imposing base independence as a reasonable description of preferences. The rejection of base independence either reflects the true dependence of the equivalence scale equation on expenditures or is an artifact of restrictive parametric assumptions about the functional form of the demand system. To parametrically estimate Engel curves, the functional form of the equations must be specified in advance, directly or indirectly, through the specification of the analytical formula of the utility or cost functions. An erroneous specification of the underlying microeconomic model could have serious consequences for the results. To avoid specifying functional forms, Gozalo (1997) and Pendakur (1999) introduce a nonparametric and semiparametric model of equivalence scales respectively. These models allow estimating equivalence scales for each commodity group separately. However, when estimating equivalence scales under base independence in single equations for each commodity group separately, one important implication of base independence is not considered. Base independence implies that the equivalence scale must be the same for all commodities. Therefore, Blundell, Duncan and Pendakur (1998) extend the approach to a system of expenditure share equations - the so-called extended partially linear model. This method identifies equivalence scales from nonlinearities in the demand functions. Linear or quadratic parametric demand functions would not allow for nonlinearities. The extended partially linear model, however, is a more flexible because the expenditure shares are fully nonparametric. Moreover, the extended partially linear model is preference consistent and yields the same estimated equivalence scale for all commodity groups.

In this paper, Blundell, Duncan and Pendakur's (1998) extended partially linear model is applied on recent versions of the Swiss Household Budget Survey to estimate equivalence scales. This paper focuses on providing new results for Switzerland by applying a less restricting, semiparametric estimation approach. To my knowledge, it is the first comprehensive application of this method using Swiss data. Furthermore, this paper aims to compare the obtained results to the results from earlier contributions based on parametric demand systems using the same or similar data bases (see, e.g., Gerfin and Wanzenried, 2001; Gerfin et al., 2009). The applied method yields the following results: the estimated equivalence scale for childless couples to singles is 1.25 , the estimated estimated equivalence scale for the comparison of couples with one child with childless couples is 1.22 , and 1.28 for the comparison of couples with two children to childless couples. 
The remainder of the paper is organized as follows. The next section introduces the theoretical framework and presents the assumptions necessary to identify equivalence scales. Section 3 gives a brief overview of the estimation strategy. The main characteristics of the data source and the selected sample are reported in Section 4. Section 5 presents estimates of equivalence scales for single equations and for the extended partially linear model, and provides tests for base independence. Section 6 explains how the estimated results can be used to infer cost of children and compares those with other results currently available in the literature. The last section concludes.

\section{Consumer Theory}

Consider a household with a finite dimensional vector of observable characteristics $\mathbf{z}$ and total expenditures $x$ that faces a $(1 \times m)$-vector $\mathbf{p}$ of prices of $m$ different goods. Given a linear budget constraint, the household chooses the bundle of goods that maximizes its utility. The expenditure function is given by

$$
x=C(\mathbf{p}, u, \mathbf{z}),
$$

and defines the minimum expenditure required for a household with demographic characteristics $\mathbf{z}$ facing prices $\mathbf{p}$ to attain utility level $u$. Equivalence scale $D(\mathbf{p}, u, \mathbf{z})=C(\mathbf{p}, u, \mathbf{z}) / C(\mathbf{p}, u, \overline{\mathbf{z}})$ relates the expenditures of a household with characteristics $\mathbf{z}$ to the expenditures of a reference household with characteristics $\overline{\mathbf{z}}$. The functional form of the expenditure functions is left unspecified. However, the equivalence scale $D(\mathbf{p}, u, \mathbf{z})$ can not be identified because it varies with the unobserved utility level $u$ at which the comparison is made. Therefore, additional information or not testable restrictions on preferences over the two household types are needed to identify equivalence scales.

As mentioned, LEW BEL (1989) solves the identification problem by assuming that the equivalence scale is base independence. That is, invariant with respect to the utility level at which the comparison is made. He shows that the expenditure functions must be related by

$$
C(\mathbf{p}, u, \mathbf{z})=C(\mathbf{p}, u, \overline{\mathbf{z}}) \Delta(\mathbf{p}, \mathbf{z}),
$$

if there exists a base independent equivalence scale function $\Delta(\mathbf{p}, \mathbf{z})$ which varies with price $\mathbf{p}$ and household characteristics $\mathbf{z}$, but is independent of $u$. That is, the equivalence scale is the same for all households with equal characteristics across 
all utility levels. In other words, the equivalence scale is independent of expenditures or, equivalently, utility. The special case where the equivalence scale is also independent of $\mathbf{p}$ yields Engel scales.

Equation (2) can also be expressed in terms of the dual indirect utility functions, $V(\mathbf{p}, x, \mathbf{z})$, which give the level of the utility of a household with characteristics $\mathbf{z}$ with total expenditures $x$ at prices $\mathbf{p}$.

$$
V(\mathbf{p}, x, \mathbf{z})=V\left(\mathbf{p}, \frac{x}{\Delta(\mathbf{p}, \mathbf{z})}, \overline{\mathbf{z}}\right)
$$

Defining $x / \Delta(\mathbf{p}, \mathbf{z})$ as the equivalent expenditure, that is, the expenditure level needed to bring the utility of a reference household to the level of utility of a household with characteristics $\mathbf{z}$, implies that if two households facing the same prices have the same equivalent expenditure, then they are equally well off.

As stated above, the base independence assumption implies a restriction on household preferences across household types. As shown by Pendakur (1999), base independence also implies restrictions on the shape of expenditure share equations across household types. That is, the Marshallian shares of a nonreference household are equal to the Marshallian share of the reference household at the same equivalent expenditure plus the elasticity of the equivalence scale with respect to $\mathbf{p}$ :

$$
w(\mathbf{p}, x, \mathbf{z})=w\left(\mathbf{p}, \frac{x}{\Delta(\mathbf{p}, \mathbf{z})}, \overline{\mathbf{z}}\right)+n(\mathbf{p}, \mathbf{z}),
$$

where $w(\cdot)$ is the Marshallian budget share vector. Consequently, the equivalent expenditure is proportional to household expenditure if base independence is satisfied.

Equation (4) shows that under base independence the shape of the budget share function is the same for particular goods across household types. The Engel curves are, however, not restricted to particular shapes. The relationship is visualized in Figure 1. The budget share functions of the reference and the non-reference household must be related by a horizontal and a vertical shift. The basic idea of the estimation approach is therefore to derive (the log of) the equivalence scale $\delta$ by estimating the horizontal shift between the budget share functions for the reference and non-reference households. An estimate for the scale elasticity $\eta$ is given by the vertical shift. This estimation approach is consistent with 
consumer theory, accounts for demographic decomposition and is nonlinear in $\log$ of total expenditure. ${ }^{2}$

As noted, the Engel curves for particular goods must have the same shape across household types. Pendakur (1999) calls this restriction shape invariance. Shape invariance is a testable necessary condition for the base independence assumption, however, not a sufficient condition. A test for shape invariance is discussed in Section 5.3.

Figure 1: Log of the Equivalence Scale and Scale Elasticity

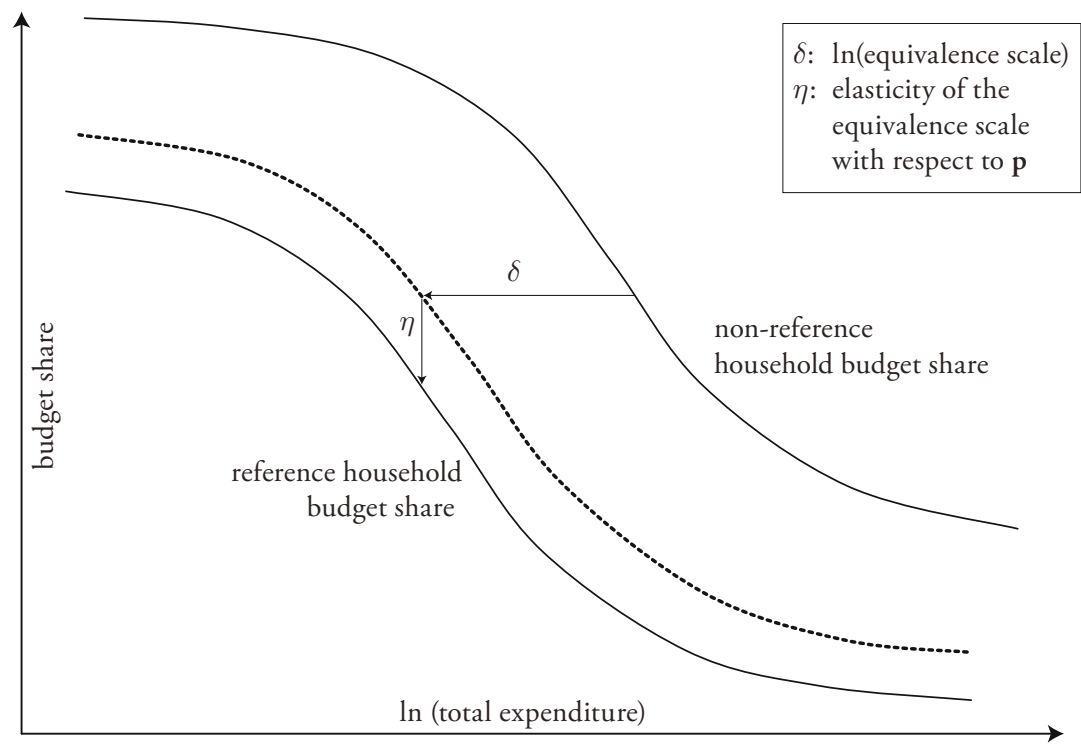

2 To estimate unique equivalence scales under base independence using demand data, expenditure share equations have to be nonlinear. Pendakur (1999) therefore proposes to estimate expenditure share equations using either log-quadratic or nonparametric regression. 


\section{Estimation of Base-Independent Equivalence Scales}

As mentioned above, the basic idea of the estimation approach is to derive (the $\log$ of) the equivalence scale $\delta$ by estimating the horizontal shift between the budget share functions for the reference and non-reference households that is visualized in Figure 1. For notational simplicity, I restrict the overview of the estimation model for a single good. Since the price remains constant, the budget share functions are defined as Engel curves. I consider two types of households, the reference household $a$ and non-reference household $b$. Suppose $x$ is the $\log$ of total expenditure and $y$ is the share of a single good purchased by the household. The Engel curve $y=f_{z}(x)$ of a single good for a household with characteristics $\mathbf{z}$ is then specified as a function $f_{z}(\cdot)$ of the $\log$ of total expenditure $x$. Under base independence, the Engel curves of household type $a$ and $b$ are linked by

$$
f_{b}\left(x_{b}\right)=f_{a}\left(x_{b}-\delta\right)+\eta,
$$

where $f_{z}\left(x_{z}\right)$ is the share of a single good purchased by household type $z=a, b, \delta$ is the $\log$ of the equivalence scale and $\eta$ is the elasticity of the equivalence scale with respect to the price of the single good. The system satisfies base independence if $\delta$ and $\eta$ do not depend on $x$. Considering a base independent system of Engel curves with given prices, both $\delta$ and $\eta$ are constants.

But how can this horizontal shift parameter $\delta$ be estimated? As outlined formally below, an estimate for the log of the equivalence scale $\delta$ can be obtained in two steps. In the first step, the Engel curves of the reference household $a$ and non-reference household $b$ have to be estimated. In the second step, the log of the equivalence scale $\delta$ can be estimated by minimizing a loss function that measures the quadratic distance between the two Engel curves with respect to $\delta$. The exponential transformation of the horizontal shift, i.e. $\exp (\delta)$, is the equivalence scale.

To avoid specifying functional forms, a semiparametric approach is applied in this paper. That is, the Engel curves for the non-reference and reference households are estimated nonparametrically for each commodity. The equivalence scale is then estimated as a parameter in the demand system that is defined by the estimated Engel curves. Whereas the shape of the function $f_{z}(\cdot)$ for $z=a, b$ may differ for each good, the horizontal shift parameter $\delta$ is constant for all goods. The main advantage of the semiparametric approach is that the model specifies a functional from for the equivalence scale, but leaves the Engel curves unrestricted. Thus, the model imposes rather weak restrictions on the Engel curves and it allows for a broad class of functional forms in the empirical analysis. 
As mentioned above, the nonparametric functions $f_{z}(\cdot)$ are estimated first. For a given number of observations $n_{z}$ for $z=a, b$ an estimate of $f_{z}(x)$ can be found using the so called local constant kernel estimator, originally proposed by NADARAYA (1965) and Watson (1964):

$$
\hat{f}(x)=\frac{\sum_{i=1}^{n} y_{i} K\left(\frac{x_{i}-x}{h}\right)}{\sum_{i=1}^{n} K\left(\frac{x_{i}-x}{h}\right)} .
$$

$K(\cdot)$ refers to the Gaussian kernel function. $h$ is the bandwidth which is computed by the fully data-driven least square cross-validation method, originally proposed by Rudemo (1982), Stone (1984) and Bowman (1984) (see also Li and Racine, 2006, pp. 15-19).

The second step of the estimation method is to estimate the log of the equivalence scale $\delta . \delta$ is estimated by minimizing a loss function. The loss function is defined as the quadratic distance between the Engel curves of the two household types. Here, the loss function proposed by Sun, STEngos and WANG (2006) is used:

$$
\hat{S}(\delta, \eta)=S(\delta, \eta)+\max (x)-\min (x),
$$

where the function $S(\delta, \eta)$ is defined as

$$
\begin{aligned}
S(\delta, \eta) & =\int_{-\infty}^{\infty}\left(\hat{f}_{b}(u)-\eta-\hat{f}_{a}(u)\right)^{2} K\left(\frac{u-\bar{x}}{h}\right) d u \\
& \approx \sum_{i=1}^{n}\left(\hat{f}_{b}\left(x_{i}\right)-\eta-\hat{f}_{a}\left(x_{i}\right)\right)^{2} .
\end{aligned}
$$

Since the nonparametric kernel methods cannot produce precise estimates for the sample tails, the loss function includes a penalty term $(\min (x)-\max (x))$. This penalty term is a restriction on the value of $\delta$ that accounts for the degree to which the two sample sets $\left(x_{a}, y_{a}\right)$ and $\left(x_{b}-\delta, y_{b}-\eta\right)$ overlap. The larger the range the two sets overlap, the smaller the penalty value. One can think of the penalty term as a variance-reducing device. It moves the estimation away from the tails and to the center of the sample. Hence, the two sets are moved as close as possible by minimizing the loss function $\hat{S}(\delta, \eta)$ over $\delta$ and $\eta$. Sun, Stengos 
and WANG (2006) show that the penalty term is asymptotically independent of $\delta$. Most loss functions in earlier contributions (see, e.g., Pendakur, 1999) only use information from the non-reference type of households and leave half of the information unexploited. However, equation (5) implies that

$$
\begin{aligned}
& f_{b}\left(x_{b}\right)-\eta=f_{a}\left(x_{b}-\delta\right) \\
& f_{b}\left(x_{a}+\delta\right)-\eta=f_{a}\left(x_{a}\right),
\end{aligned}
$$

where $\hat{f}_{b}(x)$ is the nonparametric function based on points $\left(x_{b}-\delta, y_{b}\right)$ and $\hat{f}_{a}(x)$ is the nonparametric function based on points $\left(x_{a}, y_{a}\right)$. Hence the nonparametric regressions based on the sample sets $\left(x_{a}, y_{a}\right)$ and $\left(x_{b_{A}}-\delta, y_{b}-\eta\right)$ should be identical. Furthermore, $\hat{f}_{b}\left(x_{b}\right)-\eta$ and $\hat{f}_{a}\left(x_{b}-\delta\right)$ as well as $\hat{f}_{b}\left(x_{a}-\delta\right)-\eta$ and $\hat{f}_{a}\left(x_{q}\right)$ should define the same curve if base-independence is satisfied. The loss function $\hat{S}(\delta, \eta)$ therefore relies on all observations of the total expenditures from both household types.

In conclusion, the loss function $\hat{S}(\delta, \eta)$ is based on nonparametric Engel curves, but finally yields a parametric estimate for the equivalence scale $\delta$.

\section{Data}

The data source is the Swiss Household Budget Survey ${ }^{3}$ from 2000 to 2005 conducted by the Federal Office of Statistics. The Household Budget Survey is a nation-wide household survey that contains information on household earnings and consumption patterns. Two major Household Budget Surveys were conducted in 1990 and 1998. Since 2000, the survey is conducted on an annual basis. Households are chosen at random from the register of private telephone numbers. About 3000 households take part each year.

Since this paper does not focus on expenditure patterns of senior citizen or adolescent, all households with a reference person (person with highest income) younger than 20 or older than 60 years are excluded. Furthermore, the sample is limited to households with a reference person that is in labor force and households with at most two adults and two children younger than 16 years. Since housing costs for house owners are only measured to a limited extent, the sample is restricted to renters. ${ }^{4}$ Moreover, trimming $5 \%$ from each tail of the expenditure

3 The Swiss Household Budget Survey was previously called Household Expenditure Survey.

4 The main reason why only renters are included in the sample is that true housing costs for house owners are only measured to a limited extend. The reported housing costs for house 
distribution reduces the sample to 5609 observations. ${ }^{5}$ As noted above, there is no price variation. Prices do not uniquely determine the form of the equivalence scales. Since the elasticity of the equivalence scale will be estimated directly, the elasticity will be calculated at a single point. Therefore, the dependence of equivalence scales and elasticities on prices are henceforward neglected.

The survey observations are segmented into four different demographic groups. The household types are (i) single adults, (ii) adult couples, (iii) adult couples with one child younger than 16 years, and (iv) adult couples with two children younger than 16 years. It is worth noting that using this classification scheme allows controlling for household size and the number of children, which are among the most important characteristics in consumer demand. The application includes eight broad commodity groups; food purchased in stores, food in restaurants, entertainment, transport, communication, housing, household operations, and clothing. Food purchased in stores is defined as expenditures on food and non-alcoholic beverages for home consumption. Food in restaurants includes all expenditures on restaurant meals. Entertainment summarizes all expenditures on leisure activities (e.g. ski tickets), on equipment for leisure activities (e.g. tennis balls), on tickets for cultural and sport events, and on holidays. Transport includes expenditures for the operation of cars as well as on public transport. Communication is defined as all expenditures on phone, mail and internet services. Since the sample only includes renters, housing is defined as expenditures on rent plus expenditures on water, fuel, and electricity. Household operations summarizes the expenditures on non-food household goods as toilet paper, washing powder or soap. Clothing consists of expenditures on clothes and shoes for all household members. ${ }^{6}$

owners are often very small or even zero. As house owners are rather richer households, excluding them could potentially bias the results. The consequences of this exclusion for the estimated equivalence scales are, however, ambiguous.

5 There are two reasons why the extreme parts of the sample are omitted. Firstly, there is evidence that individuals at upper and lower end of the distribution behave quite differently from the rest (see Donaldson and Pendakur, 2004). Secondly, at the extremes, individuals tend to misrepresent their incomes and expenditures, something that introduces measurement error problems. Hence, it is customary to trim these parts out of the sample (see also YATCHEw, Sun and Deri, 2003).

6 The comparison of welfare levels of different sized household using equivalence scales is only valid, if the household consume comparable consumption bundles. As pointed out by one of the referees, this assumption is rather strong for the commodity groups food in restaurants and entertainment when focusing on the comparison between childless couples and couples with children. However, the chosen approach is common in the literature (see, e.g., Pendakur, 1999; WILKe, 2006). 
Table 1: Descriptive Statistics

\begin{tabular}{lcccc}
\hline & Singles & Couples 0 & Couples 1 & Couples 2 \\
\hline Number of observations & 2309 & 1421 & 830 & 1049 \\
Average consumption & 3369.3 & 5020.4 & 4779.6 & 4919.1 \\
& $(1231.5)$ & $(1830.2)$ & $(1698.7)$ & $(1590.7)$ \\
Median consumption & 3138.2 & 4688.6 & 4439.9 & 4662.1 \\
\hline Average shares: & & & & \\
Food purchased from stores & 0.11 & 0.14 & 0.18 & 0.20 \\
& $(0.06)$ & $(.06)$ & $(0.06)$ & $(0.07)$ \\
Food in restaurants & 0.11 & 0.11 & 0.08 & 0.07 \\
& $(0.07)$ & $(.07)$ & $(0.05)$ & $(0.05)$ \\
Entertainment & 0.12 & 0.13 & 0.10 & 0.11 \\
Transport & $(0.10)$ & $(.10)$ & $(0.08)$ & $(0.08)$ \\
& 0.11 & 0.12 & 0.11 & 0.10 \\
Communication & $(0.09)$ & $(.09)$ & $(0.08)$ & $(0.07)$ \\
& 0.04 & 0.04 & 0.05 & 0.04 \\
Housing & $(0.04)$ & $(.03)$ & $(0.03)$ & $(0.03)$ \\
\hline Household operations & 0.42 & 0.37 & 0.38 & 0.37 \\
Clothing & $(0.12)$ & $(.11)$ & $(0.10)$ & $(0.10)$ \\
& 0.03 & 0.04 & 0.05 & 0.05 \\
& $(0.06)$ & $(.06)$ & $(0.06)$ & $(0.06)$ \\
\hline
\end{tabular}

Notes: Means and standard errors in parentheses.

These commodities are chosen because each is a major category of household expenditure, each commodity plays an important role in determining material well-being, and each can be treated as expenditures for regular means of subsistence. Purchases of major durable goods are infrequent. For example, households do not usually buy a car each month, but many households enjoy the services of a car. That is, consumption of durable goods occurs over a long period of time, while the expenditure on the item generally does not. This divergence between enjoyment of the good and expenditure on the good means that the analysis of durables is difficult. The analysis is therefore restricted to non-durables, all payments for durables, e.g. expenses for car or furniture purchases, are subtracted from the expenditures in the corresponding commodity group. 
Table 1 reports descriptive statistics of the the four household types considered in this paper. Adult couples without children are denoted 'Couples 0', couples with one child 'Couples 1', and couples with two children 'Couples 2'. The median of total expenditures is CHF 3370 for single living individuals. For couples without children and two-parent families with one or two children the median expenditures vary between CHF 4440 and CHF 4690. Single living individuals spend more than $40 \%$ of their total expenditures on housing. The budget share of housing for couples with and without children is approximately one third of the total expenditures. Moreover, households with children spend a large share of total expenditures for food purchased form stores.

\section{Empirical Results}

This section provides estimates for unrestricted nonparametric Engel curves and for equivalence scales for the eight single commodities and tests whether preferences are consistent with the base independence assumption. Furthermore, the extended partially linear model is applied to estimate equivalence scale for a system of Engel curves.

\subsection{Nonparametric Regression}

Figures 2, 3 and 4 show the nonparametric estimates of the Engel curves for the eight commodity groups and for the three pairwise comparisons between the reference and non-reference households. Each figure presents Kernel regressions for the Gaussian kernel, using the local linear least square cross-validation method to compute the bandwidth. ${ }^{7}$ The resulting bandwidths are in the range between 0.14 and 0.48 .

For the Engel curves of some commodities the Working-Leser linear logarithmic formulation might have been an adequate approximation (e.g. housing and entertainment). The estimates of other commodities as food in restaurants and clothing visualize a more nonlinear relationship between the expenditure share and the log expenditures. While the Engel curves for food purchased in stores, housing, and communication are negatively sloping, the slopes of the Engel

7 All nonparametric regressions as well as the bootstrap confidence bands are computed using the np package for the software package $\mathrm{R}$ for nonparametric econometrics developed by $\mathrm{HAY}_{\mathrm{A}}$ FIELD and RACINE (2008). 


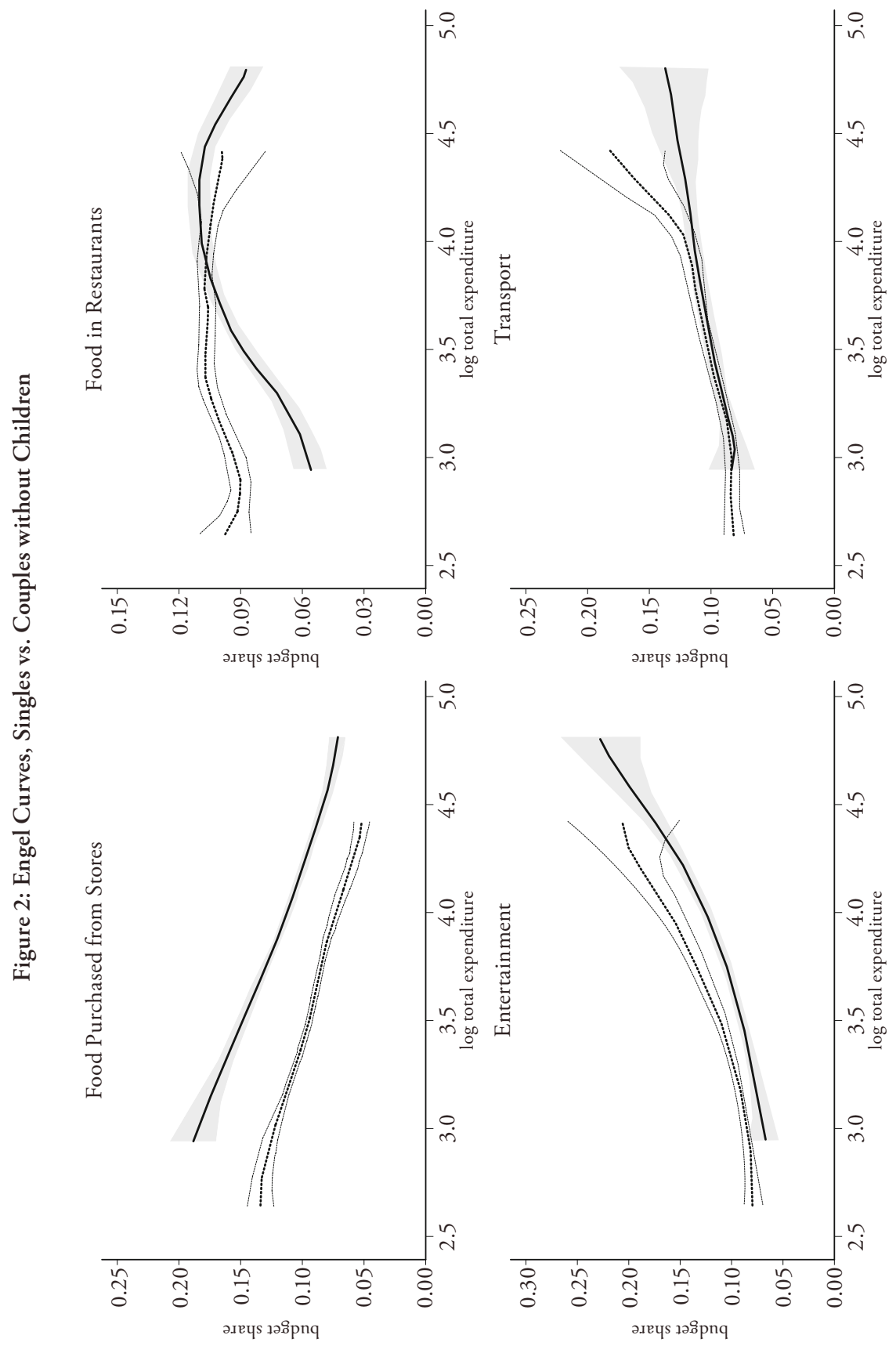

Swiss Journal of Economics and Statistics, 2012, Vol. 148 (1) 

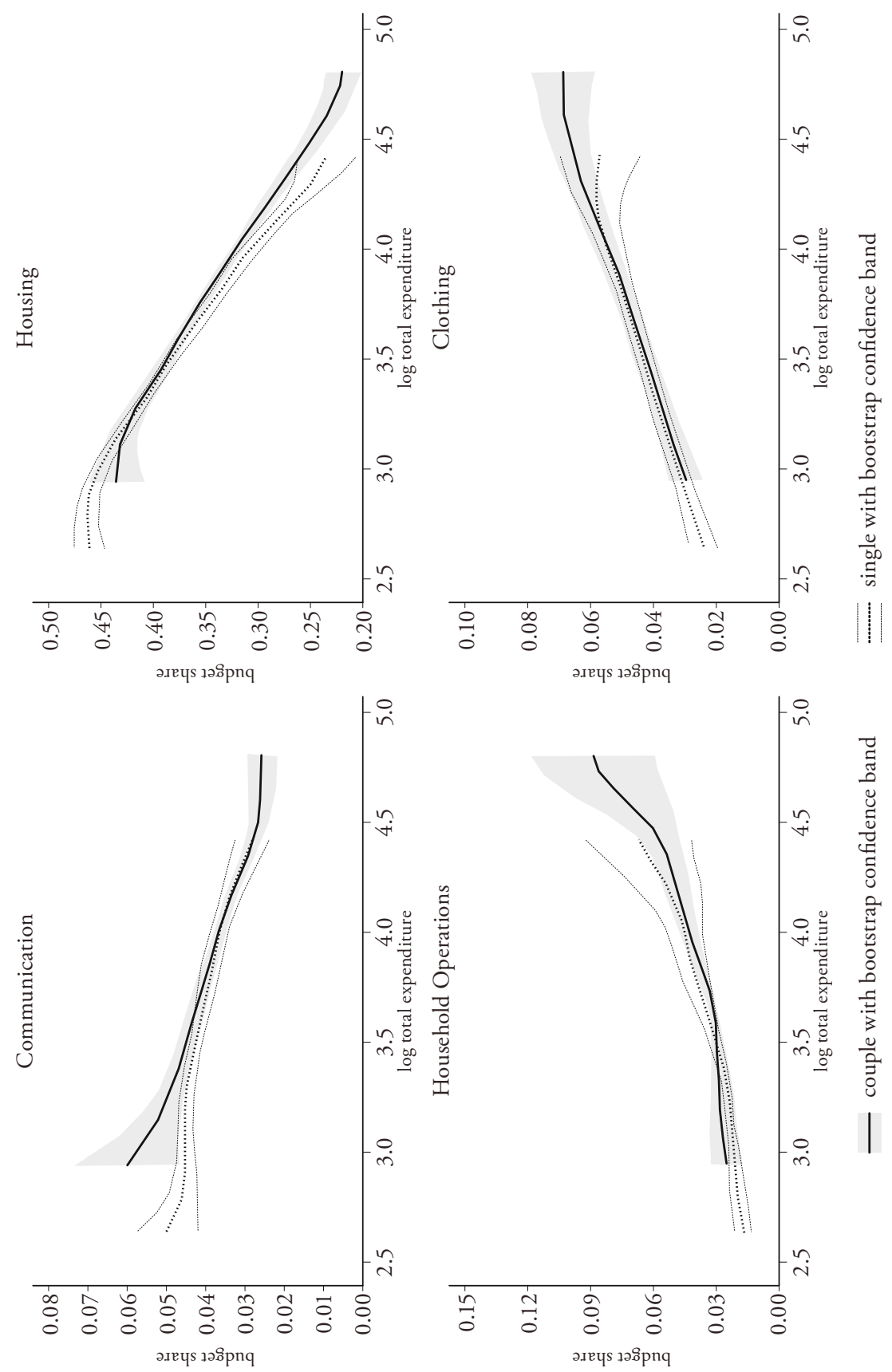


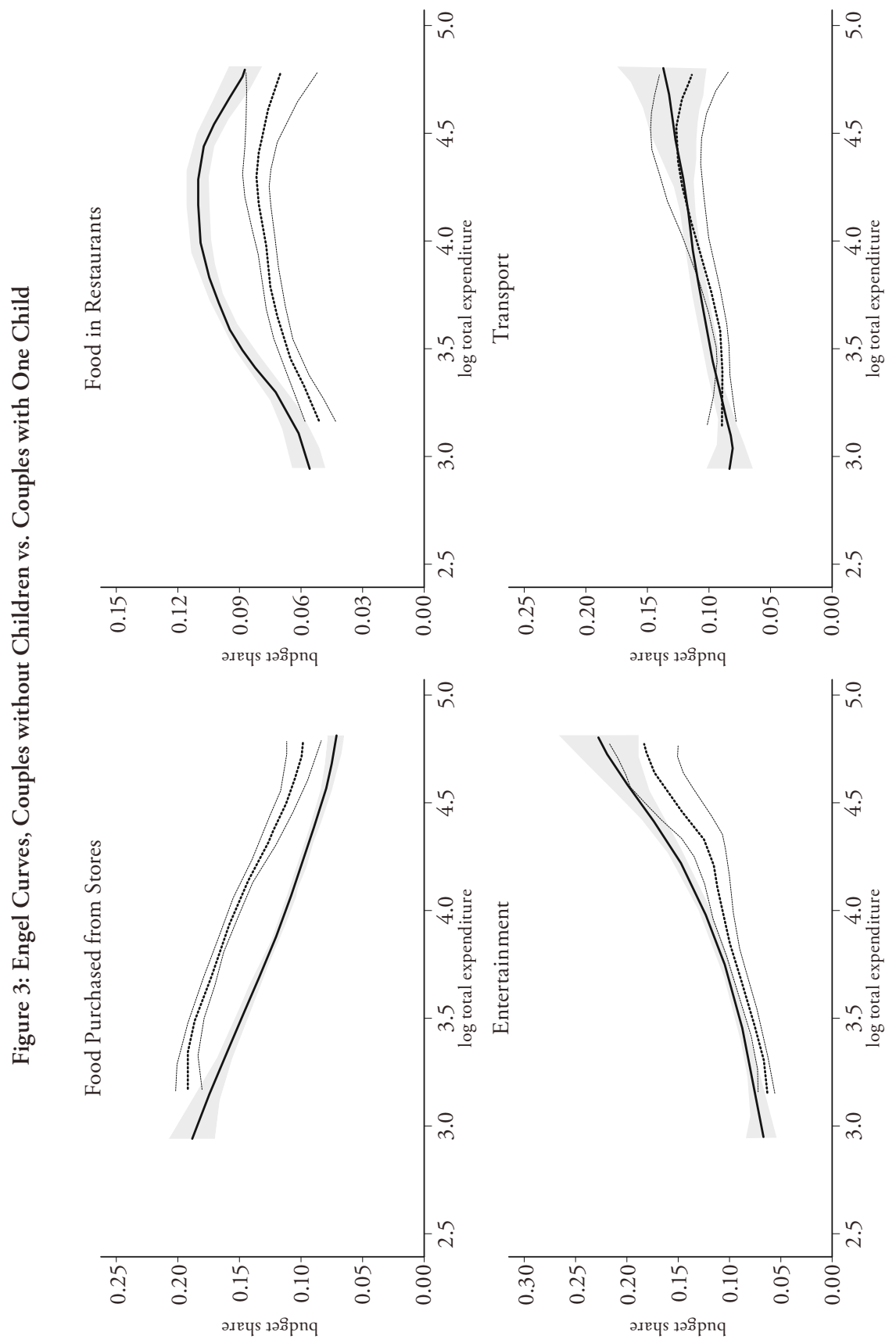

Swiss Journal of Economics and Statistics, 2012, Vol. 148 (1) 

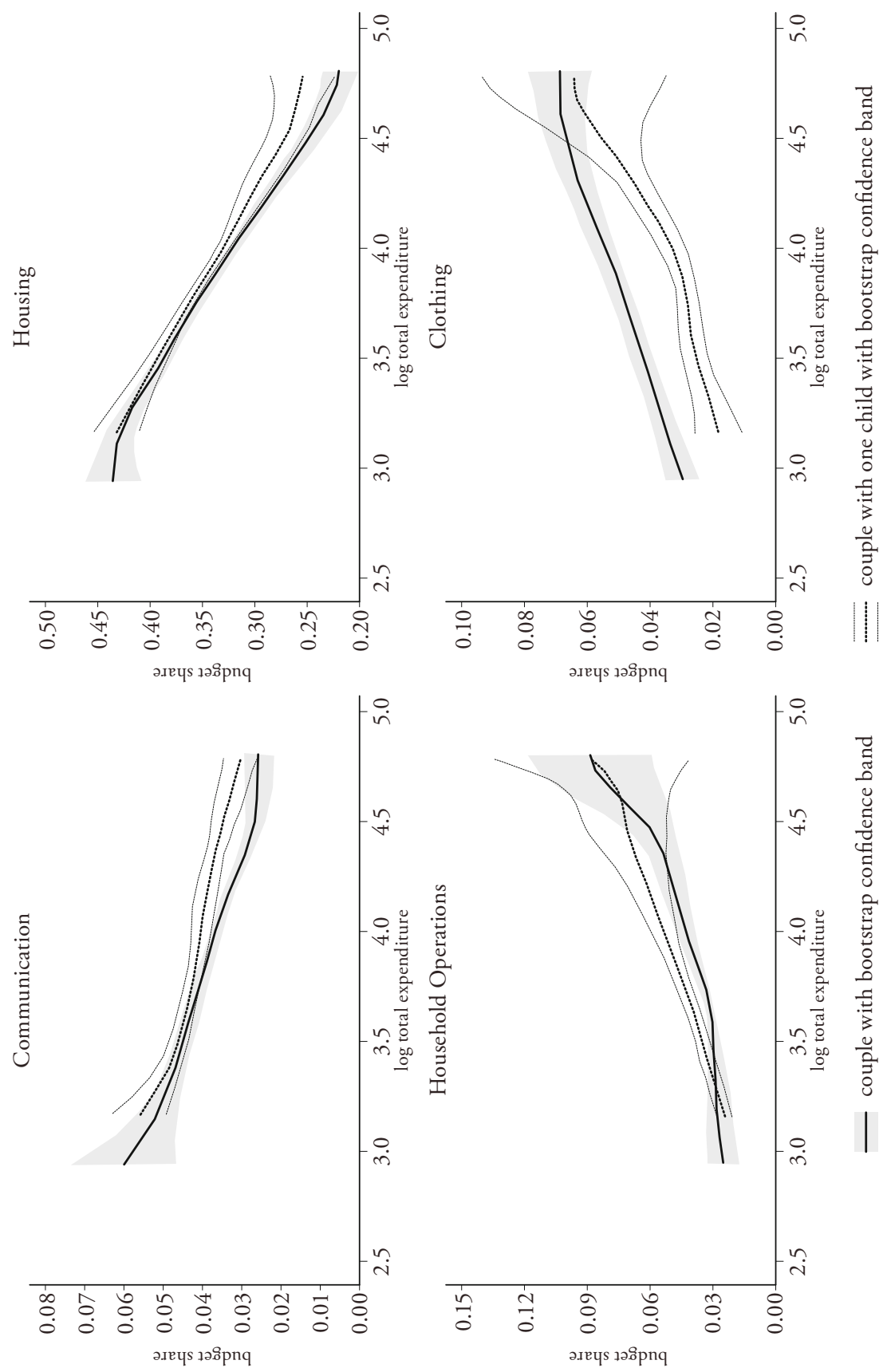


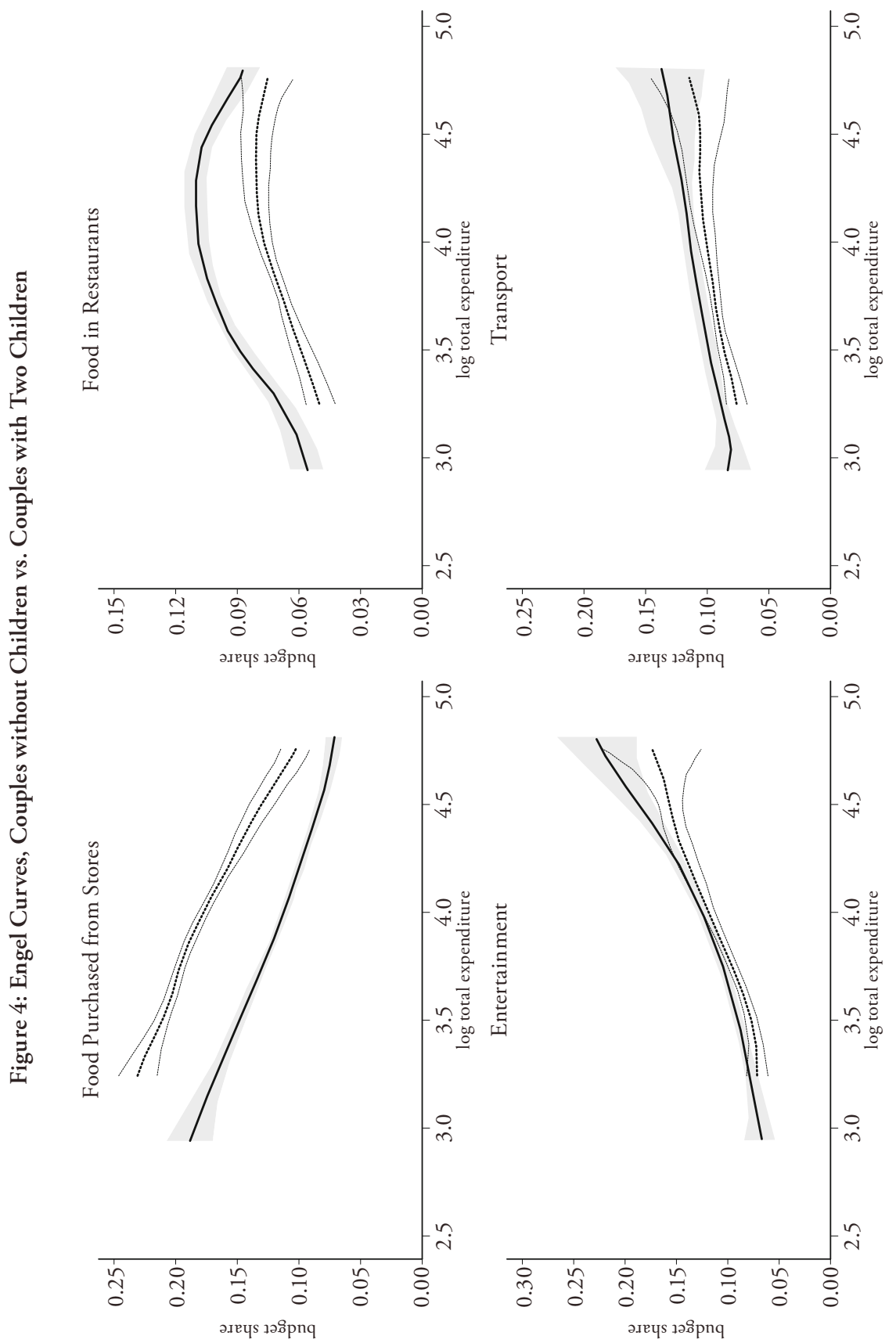



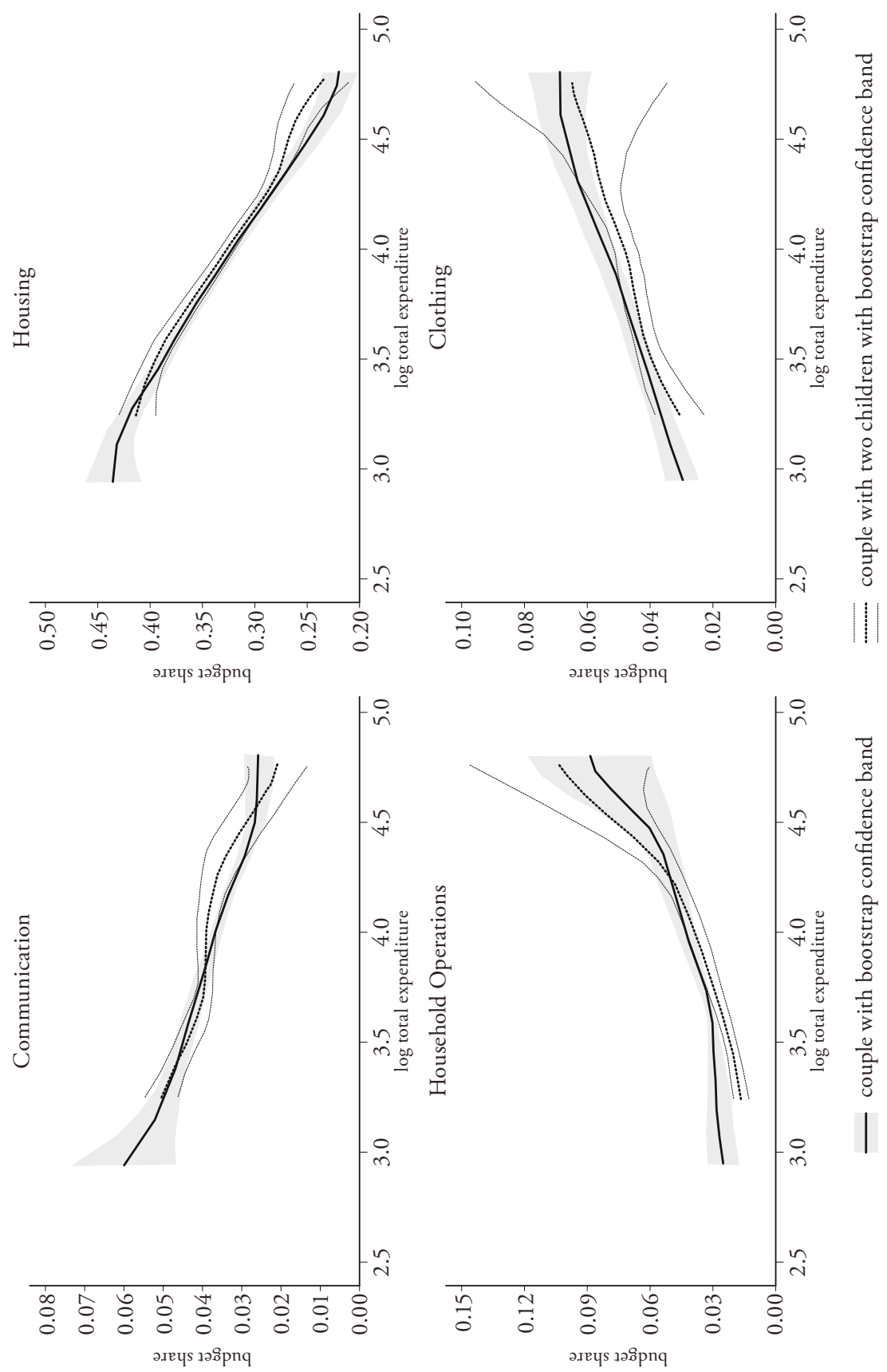
curves for entertainment, transport, household operations, and clothing are positive. The different slopes might reflect that relatively poor households spend a large part of their expenditures on necessities such as food and housing while relatively rich households can afford to spend more on luxury goods such as entertainment. The variation between the shapes of the Engel curve for the different types of households is rather small. However, the vertical distance of the Engel curves of the reference and non-reference household varies across commodities.

The Engel curves for the commodities food in restaurants and clothing are upward-sloping for most households, but downward-sloping for households with high expenditures. This might be due to the fact that there is a saturation point or an upper absolute limit for the possibility of purchasing these commodities. Moreover, the confidence bands are often wide for households with high expenditures. This is particularly true for the commodities entertainment, household operations and clothing.

\subsection{Single Equation Estimates}

As mentioned in Section 2, the basic idea of the semiparametric estimation approach described by PENDAKUR (1999) is to find the log of the equivalence scale $\delta$ that is able to best fit the estimated nonparametric expenditure share equations of two different types of households. The value of the loss function $\hat{S}(\delta)$ is minimized by applying a simple gridsearch across a wide span of values for $\delta$. Table 2 shows the estimated natural logarithm of the equivalence scale $\delta$, the confidence interval of $\ln (\delta)$, and the equivalence scale $\delta$ for each pairwise comparison between the before specified household types. ${ }^{8}$ Equivalence scales are estimated using the first mentioned household as the reference household.

The results show that the estimated value of the equivalence scales mostly increases with household size. That is, the equivalence scale estimates satisfy a household size effect. Focusing on the comparison between childless couples and childless singles, I find large economies of scale for the commodities housing and household operations. Moreover, I find a compensating effect between food purchased in stores and food in restaurants: comparing couples and singles,

8 A wild bootstrapping method with 999 bootstrap replications (see Gozalo, 1997) is used to compute confidence intervals for $\ln (\delta)$. The bootstrap errors are generated based on the distribution suggested by Mammen (1993). Different from Haerdle and Mammen (1993) who choose a larger optimal bandwidth to estimate the basic value than for the bootstrap estimates, the same optimal bandwidths is used for estimating the basic value as well as the bootstrap estimates in this study. 
Table 2: Estimation under Base Independence, Single Commodities

\begin{tabular}{lccc|ccc}
\hline & \multicolumn{3}{c|}{ Single vs. Couple 0 } & \multicolumn{3}{c}{ Couple 0 vs. Couple 1 } \\
$\begin{array}{l}\text { Expenditure } \\
\text { share equation }\end{array}$ & $\log (\delta)$ & $\begin{array}{c}\text { Confidence } \\
\text { interval }\end{array}$ & $\delta$ & $\log (\delta)$ & $\begin{array}{c}\text { Confidence } \\
\text { interval }\end{array}$ & $\delta$ \\
\hline Food purchased from stores & 0.74 & {$[0.34 ; 0.97]$} & 2.10 & 0.61 & {$[0.32 ; 0.87]$} & 1.84 \\
\hline Food in restaurants & 0.18 & {$[0.03 ; 0.39]$} & 1.20 & 0.52 & {$[0.23 ; 0.75]$} & 1.68 \\
\hline Entertainment & 0.35 & {$[0.26 ; 0.43]$} & 1.42 & 0.30 & {$[0.04 ; 0.54]$} & 1.35 \\
\hline Transport & 0.27 & {$[0.12 ; 0.54]$} & 1.31 & 0.15 & {$[0.02 ; 0.41]$} & 1.16 \\
Communication & 0.18 & {$[0.02 ; 0.37]$} & 1.20 & 0.47 & {$[0.16 ; 0.65]$} & 1.60 \\
\hline Housing & 0.04 & {$[-0.22 ; 0.35]$} & 1.04 & 0.07 & {$[-0.11 ; 0.34]$} & 1.07 \\
\hline Household operations & 0.10 & {$[-0.08 ; 0.39]$} & 1.11 & 0.05 & {$[-0.14 ; 0.33]$} & 1.05 \\
Clothing & 0.29 & {$[0.12 ; 0.48]$} & 1.34 & 0.26 & {$[0.14 ; 0.51]$} & 1.30 \\
\hline
\end{tabular}

\begin{tabular}{lccc}
\hline & \multicolumn{3}{c}{ Couple 0 vs. Couple 2 } \\
$\begin{array}{l}\text { Expenditure } \\
\text { share equation }\end{array}$ & $\log (\delta)$ & $\begin{array}{c}\text { Confidence } \\
\text { interval }\end{array}$ & $\delta$ \\
\hline Food purchased from stores & 0.74 & {$[0.31 ; 0.97]$} & 3.29 \\
\hline Food in restaurants & 0.53 & {$[0.23 ; 0.72]$} & 1.70 \\
\hline Entertainment & 0.20 & {$[0.04 ; 0.40]$} & 1.22 \\
\hline Transport & 0.16 & {$[0.03 ; 0.37]$} & 1.12 \\
Communication & 0.58 & {$[0.19 ; 0.69]$} & 1.79 \\
\hline Housing & 0.05 & {$[-0.13 ; 0.36]$} & 1.05 \\
\hline Household operations & 0.11 & {$[-0.03 ; 0.32]$} & 1.12 \\
\hline Clothing & 0.49 & {$[0.23 ; 0.68]$} & 1.63 \\
\hline
\end{tabular}

the estimated equivalence scale for food purchased in stores is 2.10 , the equivalence scale for food in restaurants is 1.20 . This finding might reflect that individuals living in couples tend to eat more at home and spend less on meals in restaurants than two singles. This shift from eating outside to eating at home might partially capture the effect of changing living arrangements when two singles move together.

For the comparison between childless couples and couples with one child, I find comparably small equivalence scales for the two categories housing or 
household operations. The equivalence scales for the commodities food purchased from stores, food in restaurants, entertainment, transport, communication, and clothing are significantly larger than one. For most commodities, the equivalence scales for the comparison between childless couples and couples with two children are similar, but slightly higher than in the previous comparison.

\subsection{Test for Shape Invariance}

So far, I estimated equivalence scales imposing that preferences satisfy base independence. As mentioned in Section 2, the Engel curves for particular goods must have the same shape across household types under base independence. Pendakur (1999) proposes a test for this shape invariance restriction (which is a necessary but not sufficient condition for base independence), that is applied here to analyze whether preferences are consistent with base independence.

Under the null hypothesis of shape invariance, $\delta$ is constants and does not depend on $x$. The test statistic evaluates whether the loss function is very large at its minimized value compared to loss functions minimized over data simulated with the assumption that base independence is satisfied.

Table 3 presents the tests for shape invariance for different household types and expenditure share categories. The shape invariance restriction is rejected for the comparison between childless couples and couples with one child for the commodity food in restaurants and for the comparison between childless couples and couples with two children for the commodity clothing. However, the assumption that Engel curves for one type of household are a linear transformation of the Engel curves for another type of household cannot be rejected for any of the 22 other comparisons. A possible explanation for the rejection of shape invariance of the commodities food in restaurants and clothing might be linked to the observation discussed in Section 5.1 that the Engel curves behave differently for households with high expenditures and might not be precisely estimated for high-expenditure households.

\subsection{System of Expenditure Share Equations}

Base independence implies that the horizontal shift parameter must be the same in all expenditure share equations. The next section addresses this issue by applying the extended partially linear model described by Blundell, Duncan and Pendakur (1998). Furthermore, this section provides tests for shape invariance in a model with restrictions of scale constancy across equations. 
Table 3: Test for Shape Invariance, Single Commodities

\begin{tabular}{|c|c|c|c|c|}
\hline \multirow[b]{2}{*}{$\begin{array}{l}\text { Expenditure } \\
\text { share equation }\end{array}$} & \multicolumn{2}{|c|}{ Single vs. Couple 0} & \multicolumn{2}{|c|}{ Couple 0 vs. Couple 1} \\
\hline & $\begin{array}{l}\text { Integrated } \\
\text { loss }\end{array}$ & $\begin{array}{c}\text { Confidence } \\
\text { interval }\end{array}$ & $\begin{array}{l}\text { Integrated } \\
\text { loss }\end{array}$ & $\begin{array}{l}\text { Confidence } \\
\text { interval }\end{array}$ \\
\hline Food purchased from stores & 1.92 & {$[1.61 ; 2.14]$} & 1.32 & {$[1.31 ; 2.12]$} \\
\hline Food in restaurants & 1.80 & {$[1.61 ; 4.98]$} & 1820.59 & {$[1.31 ; 2.95]$} \\
\hline Entertainment & 4.29 & {$[1.61 ; 5.19]$} & 1.35 & {$[1.31 ; 2.37]$} \\
\hline Transport & 5.46 & {$[1.61 ; 7.23]$} & 1.31 & {$[1.31 ; 3.65]$} \\
\hline Communication & 1.64 & {$[1.61 ; 4.56]$} & 1.31 & {$[1.31 ; 6.04]$} \\
\hline Housing & 2.55 & {$[1.61 ; 3.96]$} & 2.55 & {$[1.31 ; 5.72]$} \\
\hline Household operations & 1.64 & {$[1.61 ; 8.68]$} & 1.64 & {$[1.31 ; 14.91]$} \\
\hline Clothing & 1.88 & {$[1.61 ; 2.03]$} & 1.88 & {$[1.31 ; 5.05]$} \\
\hline
\end{tabular}

\begin{tabular}{lcc}
\hline & \multicolumn{2}{c}{ Couple 0 vs. Couple 2 } \\
$\begin{array}{l}\text { Expenditure } \\
\text { share equation }\end{array}$ & $\begin{array}{c}\text { Integrated } \\
\text { loss }\end{array}$ & $\begin{array}{c}\text { Confidence } \\
\text { interval }\end{array}$ \\
\hline Food purchased from stores & 1.32 & {$[1.30 ; 96.21]$} \\
\hline Food in restaurants & 80.20 & {$[1.30 ; 105.90]$} \\
\hline Entertainment & 1.63 & {$[1.30 ; 70.82]$} \\
\hline Transport & 1.30 & {$[1.30 ; 42.23]$} \\
Communication & 1.35 & {$[1.30 ; 59.99]$} \\
\hline Housing & 1.63 & {$[1.30 ; 25.56]$} \\
\hline Household operations & 1.30 & {$[1.30 ; 60.44]$} \\
\hline Clothing & 1.29 & {$[1.30 ; 83.25]$} \\
\hline
\end{tabular}

The estimation of the equivalence scales in the extended partially linear model is analogous to the single equation estimates: I use a simple gridsearch to minimize the value of a common loss function for all commodity groups to find a common shift parameter $\delta$. The scale elasticity $\eta$ is allowed to differ for each commodity group. The common loss function is a weighted sum of the integrated loss for the eight commodity groups. If shape invariance is satisfied and the size of the equivalence scale is the same across all equations, this method yields a consistent estimator of the true parameters (see Pinkse and Robinson, 1995). Estimates 
of the equivalence scales for the system of expenditure share equations for each pairwise comparison between the before specified household types are presented in Table 4. Relative to a single adult household, a two adult household has an estimated equivalence scale of 1.25 . That is, a couple household must spend 1.25 times more than an otherwise similar single household to be as well-off. This suggests that the marginal cost of the second adult is 25 percent of a single adult household's expenditures.

Table 4: Estimation under Base Independence, System of Expenditure Share Equations

\begin{tabular}{lccc}
\hline $\begin{array}{l}\text { Expenditure } \\
\text { share equation }\end{array}$ & $\begin{array}{c}\text { Single } \\
\text { vs. Couple 0 }\end{array}$ & $\begin{array}{c}\text { Couple 0 } \\
\text { vs. Couple 1 }\end{array}$ & $\begin{array}{c}\text { Couple 0 } \\
\text { vs. Couple 2 }\end{array}$ \\
\hline Log equivalence scale & 0.22 & 0.2 & 0.25 \\
Confidence interval & {$[0.16 ; 0.28]$} & {$[0.13 ; 0.27]$} & {$[0.20 ; 0.30]$} \\
Equivalence scale & 1.25 & 1.22 & 1.28 \\
\hline Integrated Loss & 1141.37 & 1662.23 & 1844.55 \\
Confidence interval & {$[222.0 ; 1883.4]$} & {$[177.7 ; 1701.6]$} & {$[211.8 ; 1761.5]$} \\
\hline
\end{tabular}

The estimated equivalence scales for the comparison of childless couples with couples with one child and couples with two children are 1.22 and 1.28, respectively. That is, the marginal cost of the first child is 22 percent of a couple's expenditures. Furthermore, the marginal cost of the second child is much lower (6\%). The parameters reflect the economies of scale within families and outline the extent to which the marginal cost of children declines with the number of children. ${ }^{9}$

Table 4 shows tests for shape invariance which also impose constant scales across equations. Analogous to the test for single equations, the test statistic evaluates whether the loss function is very large at its minimized value compared to loss functions minimized over data simulated based on the assumption that base

9 Browning and Meghir (1991) emphasize that estimates of the effect of young children on household demand might be biased if labor supply is not taken into account. To consider for the effect of female labor supply, I also estimate equivalence scales that distinguish between households with one and with two working adults. The estimated values differ slightly, but the estimates are not significantly different. Therefore, the distinction between families with one or two working adults is henceforward neglected. 
independence is satisfied. The shape invariance assumption cannot be rejected for two of the three comparisons. The test, however, rejects shape invariance and therefore the base independence assumption for the comparison between childless couples and couples with two children. ${ }^{10}$ However, to test for shape invariance in a system of equation, the assumption that $\delta$ is equal across all equations must hold. Therefore, the value of the loss function at its minimized point might also reflect the differences in the horizontal distance of the reference and non-reference household's Engel curves for the eight different commodities.

\subsubsection{Sensitivity Analysis}

As discussed above, the estimated equivalence scale for the comparison of a childless couple and a single household is 1.25 . This estimated equivalence scale is slightly smaller than the scale of the Swiss social benefit system. ${ }^{11}$ Yet, the differences are not significant. Possible explanation for the difference is that the rent is not included in the expert scales and that only low income households are the target group of the social benefit systems. As discussed by Donaldson and Pendakur (2004), who estimate a model that allows the equivalence scales to differ by expenditure level, equivalence scales decrease with household expenditures. ${ }^{12}$ Equivalence scales that are estimated with data from the middle of the distribution of welfare might therefore understate the poverty rates and the needs of poor households. The previously presented results should therefore not be directly used for policy recommendation. To consider the need of low income households, the estimation method is applied on a sample that only includes the lowest or the highest quartile of the income distribution as in WILKE (2006). The results presented in Tables 5 and 6 show that households with low income have a tendency towards higher equivalence scales and the estimated results for the comparison of childless couples with single households are closer to the expert scale suggested by the Swiss social benefit system. However, splitting the sample increases the variance of the estimations and there are no significant differences

10 The failure of the shape invariance test implies that the observed consumer behavior can be used for unambiguous comparisons of changes in but not levels of welfare (BLUNDELL and LEWBEL, 1991).

11 The expert scales provided by the Swiss social benefit system (SKOS, 2009) suggest that couple household must spend 1.53 times more than an otherwise similar single household to attain the same standard of living.

12 Donaldson and Pendakur's (2004) study is based on a generalization of the assumption of equivalence scale exactness (or independence of base). The model provides less restrictive household demands and allows equivalence scales to depend on expenditures. 
between the estimated equivalence scales for low and for high income households. A larger data sample would be needed to estimate more accurate equivalence scales for income level households.

Table 5: Estimated Equivalence Scales, Lowest Income Quartile

\begin{tabular}{lccc}
\hline $\begin{array}{l}\text { Expenditure } \\
\text { share equation }\end{array}$ & $\begin{array}{c}\text { Single } \\
\text { vs. Couple 0 }\end{array}$ & $\begin{array}{c}\text { Couple 0 } \\
\text { vs. Couple 1 }\end{array}$ & $\begin{array}{c}\text { Couple 0 } \\
\text { vs. Couple 2 }\end{array}$ \\
\hline Log equivalence scale & 0.27 & 0.22 & 0.29 \\
Confidence interval & {$[0.17 ; 0.37]$} & {$[0.13 ; 0.31]$} & {$[0.19 ; 0.39]$} \\
Equivalence scale & 1.31 & 1.25 & 1.34 \\
\hline
\end{tabular}

Table 6: Estimated Equivalence Scales, Highest Income Quartile

\begin{tabular}{lccc}
\hline $\begin{array}{l}\text { Expenditure } \\
\text { share equation }\end{array}$ & $\begin{array}{c}\text { Single } \\
\text { vs. Couple 0 }\end{array}$ & $\begin{array}{c}\text { Couple 0 } \\
\text { vs. Couple 1 }\end{array}$ & $\begin{array}{c}\text { Couple 0 } \\
\text { vs. Couple 2 }\end{array}$ \\
\hline Log equivalence scale & 0.21 & 0.19 & 0.23 \\
$\begin{array}{l}\text { Confidence interval } \\
\text { Equivalence scale }\end{array}$ & {$[0.10 ; 0.32]$} & {$[0.10 ; 0.28]$} & {$[0.12 ; 0.34]$} \\
\hline
\end{tabular}

As mentioned in Section 4, the data sample was trimmed (5\% of each tail of the expenditure distribution) since individuals at the extreme parts of the distribution might behave differently from the rest and since individuals at the extremes might also misrepresent their expenditures. However, this selection of the sample conditional on expenditures contradicts the base independence assumption, i.e. that equivalence scales are independent of the expenditure level. As a sensitivity check, Tables 7 and 8 report the estimation results for the system of expenditure share equations for the full sample and a trimmed sample where only $2.5 \%$ of each tail of the expenditure distribution were excluded. The results vary only to a very small extend compared to the preferred sample specification.

To check whether the results are sensitive with respect to parametric restrictions, a parametric nonlinear least square estimator which imposes a log-quadratic specification of the expenditure share is applied to estimate the Engel curves. The results in Table 9 are based on a parametric nonlinear least square estimator which imposes a log-quadratic specification of the expenditure share equation. 
Similar to Wilke (2006), the estimated results are smaller than the results of the semiparametric method. This might be some evidence that the strong parametric restrictions lead to a systematic estimation bias of the parametric estimator. The estimated wild bootstrap standard errors are similar but slightly smaller in the parametric case. However, under base independence, the coefficient on the square of the log expenditures must be nonzero (see Pendakur, 1999). If the second order term is zero, then the quadratic model collapses to a linear model and the demand cannot uniquely identify the equivalence scales. As the estimated coefficient of the second order term of some commodity groups is not statistically different from zero, the semiparametric estimator has a clear advantage.

Table 7: Estimated Equivalence Scales, no Trimming

\begin{tabular}{lccc}
\hline $\begin{array}{l}\text { Expenditure } \\
\text { share equation }\end{array}$ & $\begin{array}{c}\text { Single } \\
\text { vs. Couple 0 }\end{array}$ & $\begin{array}{c}\text { Couple 0 } \\
\text { vs. Couple 1 }\end{array}$ & $\begin{array}{c}\text { Couple 0 } \\
\text { vs. Couple 2 }\end{array}$ \\
\hline Log equivalence scale & 0.21 & 0.20 & 0.26 \\
$\begin{array}{l}\text { Confidence interval } \\
\text { Equivalence scale }\end{array}$ & {$[0.13 ; 0.29]$} & {$[0.16 ; 0.24]$} & {$[0.19 ; 0.33]$} \\
\hline
\end{tabular}

Table 8: Estimated Equivalence Scales, 2.5\% Trimming

\begin{tabular}{lccc}
\hline $\begin{array}{l}\text { Expenditure } \\
\text { share equation }\end{array}$ & $\begin{array}{c}\text { Single } \\
\text { vs. Couple 0 }\end{array}$ & $\begin{array}{c}\text { Couple 0 } \\
\text { vs. Couple 1 }\end{array}$ & $\begin{array}{c}\text { Couple 0 } \\
\text { vs. Couple 2 }\end{array}$ \\
\hline Log equivalence scale & 0.20 & 0.20 & 0.25 \\
Confidence interval & {$[0.14 ; 0.26]$} & {$[0.13 ; 0.27]$} & {$[0.17 ; 0.33]$} \\
Equivalence scale & 1.22 & 1.22 & 1.28 \\
\hline
\end{tabular}

Table 9: Estimated Equivalence Scales, Parametric Estimation Method

\begin{tabular}{lccc}
\hline $\begin{array}{l}\text { Expenditure } \\
\text { share equation }\end{array}$ & $\begin{array}{c}\text { Single } \\
\text { vs. Couple 0 }\end{array}$ & $\begin{array}{c}\text { Couple 0 } \\
\text { vs. Couple 1 }\end{array}$ & $\begin{array}{c}\text { Couple 0 } \\
\text { vs. Couple 2 }\end{array}$ \\
\hline Log equivalence scale & 0.19 & 0.21 & 0.22 \\
Confidence interval & {$[0.14 ; 0.24]$} & {$[0.17 ; 0.25]$} & {$[0.18 ; 0.26]$} \\
Equivalence scale & 1.21 & 1.23 & 1.25 \\
\hline
\end{tabular}




\section{Cost of Children}

Many aspects of household economic behavior are related to the presence of children in the household. In particular, young children are associated with lower labor supply by their mothers, older children are associated with higher household consumption. Children affect the allocation of a given budget and parents divert considerable resources to their children. Empirically, it is very difficult to directly determine the cost of children, because existing data sets do not identify the private consumption of children for commodities such as food or housing. Considerable work has been carried out on measuring the cost of a child (see, e.g., Deaton and Muellbauer, 1986; Deaton, Ruiz-Castillo and Thomas, 1989; Phipps, 1998). Most studies rely on the household consumption survey data and focused on the relationship between the demographic structure of the household and the distribution of expenditures. Typically, equivalence scales are used: equivalence scales compare the welfare levels of households with different demographic profiles. If the demographic profile of two families varies only in relation to the number of children, the equivalence scale will measure the cost of children.

Having said that, the results of the previous section allow estimating the cost of children. For example, a childless couple with mean expenditures of CHF 5020 per month would require an extra CHF 1104 per month with the addition of one child to the household, for all individuals to have the same standard of living. If the same childless couple had added two children to the family, additional expenditure requirements would be CHF 1406 per month. The assumption of economies of scales in the dimension of the household does hold here, as the cost of households is a concave function of the number of children. The sample average expenditures of families with children, however, are a lot lower than the equivalent expenditure. Because households face a budget constraint, families do not have enough income to keep increasing total expenditures on children as the number of children increases. Costs of children are therefore mainly financed by a reallocation of welfare from parents to children.

How do these results compare with earlier estimates of the cost of children? Table 10 provides a survey of studies which estimated consumption-based equivalence scales in order to derive cost of children. The estimates obtained in this paper are larger than the findings of GERFIN et al. (2009) who use a parametric estimation method and a similar data base. Hence, the semiparametric method imposing no restrictions on the shape of household Engel curves leads to different results than parametric approaches. Yet, the differences are not significant. The scales obtained in this paper do not differ significantly from most other 
scales estimates. One exception are the estimated scales for Germany (see WILKE, 2006). One main reason why the estimated scales are not statistically distinguishable is the lack of precision of the estimates. This is a general shortcoming of this literature and the discussed estimation methods.

Table 10: Comparison from the Literature of Estimated Equivalence Scales for Children

\begin{tabular}{|c|c|c|c|c|}
\hline \multirow[b]{2}{*}{ Author } & \multirow[b]{2}{*}{ Method } & \multirow[b]{2}{*}{ Data } & \multicolumn{2}{|c|}{$\begin{array}{c}\text { Estimated Equivalence Scales } \\
\text { Reference Household: } \\
\text { Childless Couple }\end{array}$} \\
\hline & & & $\begin{array}{l}\text { Couple with } \\
1 \text { Child }\end{array}$ & $\begin{array}{l}\text { Couple with } \\
2 \text { Children }\end{array}$ \\
\hline Bütikofer (this study) & $\begin{array}{l}\text { Semiparametric } \\
\text { estimation of EPLM }\end{array}$ & Switzerland & $\begin{array}{c}1.22 \\
{[1.14 ; 1.31]}\end{array}$ & $\begin{array}{c}1.28 \\
{[1.22 ; 1.38]}\end{array}$ \\
\hline Gerfin et al. (2009) & Parametric estimation & Switzerland & $\begin{array}{c}1.15 \\
{[1.09 ; 1.22]}\end{array}$ & $\begin{array}{c}1.24 \\
{[1.20 ; 1.32]}\end{array}$ \\
\hline $\begin{array}{l}\text { Stengos, Sun, and } \\
\text { Wang (2006) }\end{array}$ & $\begin{array}{l}\text { Semiparametric } \\
\text { estimation }\end{array}$ & $\begin{array}{l}\text { Canada } \\
1996\end{array}$ & $\begin{array}{c}1.15 \\
{[1.00 ; 1.32]}\end{array}$ & $\begin{array}{c}1.40 \\
{[1.22 ; 1.61]}\end{array}$ \\
\hline Wilke (2006) & $\begin{array}{l}\text { Semiparametric } \\
\text { estimation of EPLM }\end{array}$ & $\begin{array}{l}\text { Germany } \\
1998\end{array}$ & $\begin{array}{c}0.95 \\
{[0.87 ; 1.03]}\end{array}$ & $\begin{array}{l}- \\
-\end{array}$ \\
\hline $\begin{array}{l}\text { Yatchew, Sun, } \\
\text { and Deri (2003) }\end{array}$ & $\begin{array}{l}\text { Semiparametric } \\
\text { idex model }\end{array}$ & $\begin{array}{l}\text { South Africa } \\
1993\end{array}$ & $\begin{array}{c}1.03 \\
{[0.81 ; 1.25]}\end{array}$ & $\begin{array}{c}1.52 \\
{[1.19 ; 1.85]}\end{array}$ \\
\hline Phipps (1998) & $\begin{array}{l}\text { Complete } \\
\text { demand system }\end{array}$ & $\begin{array}{l}\text { Canada } \\
1978-1992\end{array}$ & $\begin{array}{c}1.16 \\
{[1.10 ; 1.21]}\end{array}$ & $\begin{array}{c}1.28 \\
{[1.18 ; 1.38]}\end{array}$ \\
\hline $\begin{array}{l}\text { Deaton, Ruiz-Castillo, } \\
\text { and Thomas (1989) }\end{array}$ & Rothbarth & $\begin{array}{l}\text { Spain } \\
1980-1981\end{array}$ & 1.22 & - \\
\hline $\begin{array}{l}\text { Deaton and } \\
\text { Muellbauer (1986) }\end{array}$ & Engel & $\begin{array}{l}\text { Sri Lanka } \\
1969-1970\end{array}$ & 1.41 & 1.77 \\
\hline $\begin{array}{l}\text { Deaton and } \\
\text { Muellbauer (1986) }\end{array}$ & Rothbarth & $\begin{array}{l}\text { Sri Lanka } \\
1969-1970\end{array}$ & 1.12 & 1.21 \\
\hline Muellbauer (1977) & Barten & $\begin{array}{l}\text { UK } \\
1968-1973\end{array}$ & 1.14 & 1.28 \\
\hline $\begin{array}{l}\text { Swiss social } \\
\text { benefit system }\end{array}$ & Expert scales & Switzerland & 1.22 & 1.40 \\
\hline
\end{tabular}

Confidence intervals in brackets if available.

a Extended partially linear model. 
As mentioned, equivalence scales allow answering the question how much additional income is required to preserve the prechild standard of living for all members of the postchild household. Answering this question is important for policy purposes. The cost of bringing up a child to parents is a function of the social norms as well as the extent of support received from outside the household. For example, for a better understanding of child poverty, the extra income required that all members of a households with different numbers of children attain the same standard of living is a useful measurement. If there is no concern about inequality within the household, the equivalence scales not only focus on the income necessary to preserve the well-being of the parents. The well-being of the children is also taken explicitly into account and children are not treated as commodities 'purchased' by adults at some costs (see also Nelson, 1989). Equivalence scales can therefore be used to design tax relief and transfer programs that equivalizes the well-being of families with different size and composition.

Of potential interest for policy makers are also single adult households with children. These household types could not be not discussed here due to very small samples of single parents with one or two children.

\section{Conclusion}

The paper presents a comprehensive empirical study of semiparametric equivalence scales for Switzerland. Equivalence scales are estimated using BLUNDELL, Duncan and Pendakur's (1998) extended partially linear model. The framework identifies equivalence scales from nonlinearities in the households' expenditure shares. This implies that the econometric framework should not impose strong restrictions on the functional form of household demand. To account for this, the estimations are based on a semiparametric specification that is consistent with consumer theory.

The extended partially linear model yields an estimated equivalence scale of 1.25 for a couple household compared to a single household. In other words, a couple requires $125 \%$ of a single's total expenditures in order to be equally welloff. The size of the estimated equivalence scale for the comparison of childless couples with couples with one child and couples with two children are 1.22 and 1.28 , respectively. That is, the marginal cost of the first child is 22 percent of a couple's expenditures.

Since equivalence scales allow answering the question how much additional income is required to preserve the prechild standard of living for all members of the postchild household, the estimated equivalence scales can be used to derive 
child cost. For example, a childless couple with mean expenditures of CHF 5020 per month would require an extra CHF 1104 per month to maintain the same living standard with the addition of one child. The additional expenditures needed for a family with two children to achieve the same level of well-being as a childless couple with mean expenditures are CHF 1406 per month. These results are comparable with earlier estimates of the cost of children in OECD countries.

There are several reasons why it is difficult to infer direct policy recommendations from these results. Since the relevant target group of social benefit systems are low income households, policy makers should base their decisions only on results for these households. A further drawback is the heterogeneity with respect to ignored variables. Moreover, the aggregation of different expenditures to commodity groups could be a source for measurement errors. As mentioned earlier, base independence implies that the equivalence scale is the same for all households with equal characteristics across all utility levels. If preferences do not satisfy base independence, the use of base-independent equivalence scales is inappropriate. There are different arguments why equivalence scales should depend on total expenditure. First, equivalence scales for multi-person households might increase with expenditures due to sharable commodities such as housing whose expenditure share decreases as total expenditure rises. Second, because the consumption of luxury goods such as meals in restaurants or cinema tickets are more enjoyable if they are consumed in groups, equivalence scales for multiperson households might decrease with expenditures. Furthermore, the applied method only focuses on the utility from consumption; utility from leisure is ignored. Therefore, the interdependence between the labor supply decision and the disposable income are not taken into account. Since the labor supply decision is certainly affected by the presence of a social benefit system, welfare comparisons are difficult when the analysis is restricted to utility from consumption. A further limitation of the analysis is that the estimation method applied in this paper ignores intra-household bargaining and within-family distribution of resources. LISE and SEITZ (2011) show that there is non-negligible inequality within households and that ignoring consumption inequality within families yields biased estimates for equivalence scales. In order to asses child cost and child poverty, it is therefore important to measure children's resource shares in households. Dunbar, Lewbel and Pendakur (2010) provide a possibility to identify children's resource shares in a collective household model. The implementation of this approach could be of particular value to analyze the allocation of resources within families and to get a more accurate measure of child poverty in developing countries. It is left for future research to investigate how child costs are affected by intra-household bargaining in Switzerland. 


\section{References}

Barten, Anton P. (1964), "Family Composition, Prices, and Expenditure Patterns", in Econometric Analysis for National Economic Planning: 16th Symposium of the Colston Society, P. Hart, L. Mills, and J. K. Whitaker, eds, London: Butterworth.

Blackorby, Charles, and David Donaldson (1993), "Adult-Equivalence Scales and the Economic Implementation of Interpersonal Comparisons of Well-Being", Social Choice and Welfare, 10(4), pp. 335-361.

Blundell, Richard, Alan Duncan, and Krishna Pendakur (1998), "Semiparametric Estimation and Consumer Demand”, Journal of Applied Econometrics, 13(5), pp. 435-461.

Blundell, Richard, and Arthur Lewbel (1991), "The Information Content of Equivalence Scales", Journal of Econometrics, 50, pp. 49-68.

Blundell, Richard, Panos Pashardes, and Guglielmo Weber (1993), "What Do We Learn about Consumer Demand Patterns from Micro Data?", The American Economic Review, 83(3), pp. 570-597.

Bowman, Adrian W. (1984), "An Alternative Method of Cross-Validation for the Smoothing of Density Estimates", Biometrika, 71(2), pp. 353-360.

Browning, Martin (1992), "Children and Household Economic Behavior", Journal of Economic Literature, 30(3), pp. 1434-1475.

Browning, Martin, and Costas Meghir (1991), "The Effects of Male and Female Labor Supply on Commodity Demands", Econometrica, 59(4), pp. 925-951.

Deaton, Angus S., and John Muellbauer (1986), "On Measuring Child Costs: With Applications to Poor Countries", Journal of Political Economy, 94(4), pp. 720-744.

Deaton, Angus S., Javier Ruiz-Castillo and Duncan Thomas (1989), "The Influence of Household Composition on Household Expenditure Patterns: Theory and Spanish Evidence", Journal of Political Economy, 97(1), pp. 179-200.

Dickens, Richard, Vanessa Fry, and Panos Pashardes (1993), "Non-Linearities and Equivalence Scales", Economic Journal, 103(417), pp.359-368.

Donaldson, David, and Krishna Pendakur (2004), "Equivalent-Expenditure Functions and Expenditure-Dependent Equivalence Scales", Journal of Public Economics, 88(1-2), pp. 175-208.

Dunbar, Geoffrey, Arthur Lewbel, and Krishna Pendakur (2010), "Children's Resources in Collective Households: Identification, Estimation and an Application to Child Poverty in Malawi”, Boston College Working Papers in Economics, 758, Boston College Department of Economics. 
EnGel, ERnst (1895), „Die Lebenskosten belgischer Arbeiter-Familien früher und jetzt“, International Statistical Institute Bulletin, 9, pp. 1-74.

Gerfin, Michael, Thomas Oesch, Heidi Stutz and Silvia Strub (2009), Kinderkosten in der Schweiz, Bundesamt für Statistik, Bern.

Gerfin, Michael, and Gabrielle Wanzenried (2001), Neue Schätzungen von Ausgaben-Äquivalenzskalen für die Schweiz, Bundesamt für Statistik, Bern.

Gozalo, Pedro L. (1997), "Nonparametric Bootstrap Analysis with Applications to Demographic Effects in Demand Functions", Journal of Econometrics, 81(2), pp. 357-393.

Härdle, Wolfgang K., and Enno Mammen (1993), "Comparing Nonparametric versus Parametric Regression Fits", The Annals of Statistics, 21(4), pp. 1926-1947.

Hayfield, Tristen, and Jeffrey S. Racine (2008), "Nonparametric Econometrics: The np Package", Journal of Statistical Software, 27(5), pp. 1-32.

Jenkins, Stephen P. (1991), "The Measurement of Income Inequality", in Economic Inequality and Poverty, L. Osberg, ed., pp.3-38, New York: Butterworth.

Kapteyn, Arie, and Bernhard Van Praag (1978), "A New Approach to the Construction of Family Equivalence Scales", European Economic Review, 7(4), pp. 313-335.

Lewbel, Arthur (1989), "Household Equivalence Scales and Welfare Comparisons", Journal of Public Economics, 39(3), pp. 377-391.

Li, QI, and Jeffrey Scott Racine (2006), Nonparametric Econometrics: Theory and Practice, Princeton University Press.

Lise, Jeremy, and Shannon Seitz (2011), "Consumption Inequality and IntraHousehold Allocations", The Review of Economic Studies, 78, pp.328-355.

Lyssiotou, Panayiota (1997), "Comparison of Alternative Tax and Transfer Treatment of Children using Adult Equivalence Scales", Review of Income and Wealth, 43(1), pp. 105-117.

Mammen, Enno (1993), "Bootstrap and wild Bootstrap for High Dimensional Linear Models”, The Annals of Statistics, 21(1), pp. 255-285.

Muellbauer, John (1974), "Household Composition, Engel Curves and Welfare Comparisons between Households : A Duality Approach", European Economic Review, 5(2), pp. 103-122.

Nadaraya, Ėlizbar A. (1965), "On Non-Parametric Estimates of Density Functions and Regression Curves", Theory of Probability and its Applications, 10(1), pp. 186-190.

Nelson, Julie A. (1989), "Separability, Scale and Intra-Family Distribution: Some Empirical Evidence”, Papers 346, California Davis - Institute of Governmental Affairs. 
Nelson, Julie A. (1993), "Household Equivalence Scales: Theory versus Policy?”, Journal of Labor Economics, 11(3), pp. 471-493.

Pashardes, Panos (1991), "Contemporaneous and Intertemporal Child Costs : Equivalent Expenditure vs. Equivalent Income Scales”, Journal of Public Economics, 45(2), pp. 191-213.

Pendakur, Krishna (1999), "Semiparametric Estimates and Tests of BaseIndependent Equivalence Scales”, Journal of Econometrics, 88(1), pp. 1-40.

Phipps, Shelley A. (1998), "What is the Income 'Cost of a Child'? Exact Equivalence Scales for Canadian Two-Parent Families", The Review of Economics and Statistics, 80(1), pp. 157-164.

Pinkse, Joris, and Peter M. Robinson (1995), "Pooling Nonparametirc Estimates of Regression Functions with Similar Data", in Advances in Econometrics and Quantitative Economics: Essays in Honor of Professor C.R. Rao, G. S. Maddala, T. N. Srinivasan and Peter Phillips, eds., pp. 172-195, Wiley-Blackwell.

Rothbarth, Erwin (1943), "Note on a Method of Determining Equivalent Income for Families of Different Composition", in War-Time Pattern of Saving and Spending, Charles Madge, ed., vol. Appendix 4, pp. 123-130, Cambridge: Cambridge University Press.

Rudemo, Mats (1982), "Empirical Choice of Histograms and Kernel Density Estimators", Scandinavian Journal of Statistics, 9(2), pp. 65-78.

SKOS (2009), Richtlinien für die Ausgestaltung und Bemessung der Sozialhilfe, Bern: Schweizerische Konferenz für Sozialhilfe.

Stone, Charles J. (1984), "An Asymptotically Optimal Window Selection Rule for Kernel Density Estimates", Annals of Statistics, 12(4), pp. 1285-1297.

Sun, Yiguo, Thanasis Stengos, and Diandin Wang (2006), "Estimates of Semiparametric Equivalence Scales", Journal of Applied Econometrics, 21(5), pp. 629-639.

Watson, Geoffrey S. (1964), "Smooth Regression Analysis", Sankhya - The Indian Journal of Statistics, 26, pp.359-372.

Wilke, Ralf A. (2006), "Semi-Parametric Estimation of Consumption-Based Equivalence Scales: The Case of Germany", Journal of Applied Econometrics, 21(6), pp. 781-802.

Yatchew, Adonis, Yiguo Sun, and Catherine Deri (2003), "Efficient Estimation of Semiparametric Equivalence Scales with Evidence from South Africa", Journal of Business \& Economic Statistics, 21(2), pp. 247-257. 


\section{SUMMARY}

How much additional income does a couple with two children need to be equally well-off as a childless couple? This question is important for public policy decisions on social benefits or child allowances. Since equivalence scales express the change in the cost required to attain a certain welfare level when the household size and composition varies, they answer this question. This paper provides semiparametric estimates of consumption-based equivalence scales by applying the extended partially linear model to the Swiss Household Budget Survey 20002005. The results permit welfare comparisons across households and provide an indirect measure of the cost of children. 